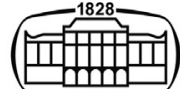

AKADÉMIAI KIADÓ

Journal of Behavioral Addictions

10 (2021) 2, 201-207

DOI:

10.1556/2006.2021.00037

(c) 2021 The Author(s)

\section{REVIEW ARTICLE}

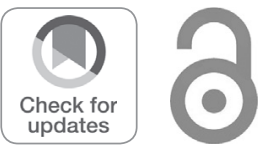

\title{
The psychology of cryptocurrency trading: Risk and protective factors
}

\author{
PAUL DELFABBRO $^{1 *} \odot$, DANIEL L. KING ${ }^{2}$ and \\ JENNIFER WILLIAMS ${ }^{3}$ \\ ${ }^{1}$ School of Psychology, University of Adelaide, South Australia, Australia \\ ${ }^{2}$ College of Education, Psychology and Social Work, Flinders University, South Australia, Australia \\ ${ }^{3}$ Department of Psychology, University of Lethbridge, Alberta, Canada
}

Received: March 15, 2021 • Revised manuscript received: May 17, 2021 • Accepted: May 22, 2021

Published online: June 19, 2021

\begin{abstract}
Background and aims: Crypto-currency trading is a rapidly growing form of behaviour characterised by investing in highly volatile digital assets based largely on blockchain technology. In this paper, we review the particular structural characteristics of this activity and its potential to give rise to excessive or harmful behaviour including over-spending and compulsive checking. We note that there are some similarities between online sports betting and day trading, but also several important differences. These include the continuous 24-hour availability of trading, the global nature of the market, and the strong role of social media, social influence and non-balance sheet related events as determinants of price movements. Methods: We review the specific psychological mechanisms that we propose to be particular risk factors for excessive crypto trading, including: over-estimations of the role of knowledge or skill, the fear of missing out (FOMO), preoccupation, and anticipated regret. The paper examines potential protective and educational strategies that might be used to prevent harm to inexperienced investors when this new activity expands to attract a greater percentage of retail or community investors. Discussion and conclusions: The paper suggests the need for more specific research into the psychological effects of regular trading, individual differences and the nature of decision-making that protects people from harm, while allowing them to benefit from developments in blockchain technology and crypto-currency.
\end{abstract}

\section{KEYWORDS}

crypto-currency, trading, harm, risk factors, protective factors

\section{INTRODUCTION: THE NATURE OF CRYPTOCURRENCY}

Cryptocurrency trading appear to be one of the fastest growing markets in the world. Surveys conducted by major exchanges (e.g., Crypto.com, 2021; Independent Reserve, 2020) suggest that hundreds of thousands of people are signing up to exchange platforms each month. The current global population of crypto-currency (crypto) buyers and sellers is now estimated to be over 106 million (Crypto.com, 2021). So rapidly is this growth occurring that figures reported as recently as three months ago are already significant under-estimates. Growth in retail investors (from the general population) is paralleled by growth in the cryptocurrency market itself. Total market capitalisation (total coins $\mathrm{x}$ market price) has now reached 1.75 trillion \$US in February 2021 after having been $\$ 550$ billion in December 2020 and \$275b in June 2020. The price of Bitcoin (BTC), the leading currency, has increased in price from $\$ 9500$ (June 2020) to a peak of $\$ 58,000$ in February 2021, with similar exponential growth observed in Ethereum (ETH) and numerous other 'altcoins' (coins other than Bitcoin). This growth in cryptocurrency value, increasing investor interest and media attention has raised some media commentary about whether the general community might be fully aware of the risks or harms that might be associated with this activity. This is particularly when media activity may focus primarily on a small minority of early investors who have achieved financial gains, largely due 
to historical factors (e.g., buying Bitcoin in 2013) or holding coins well before the onset of periodic bull cycles.

The term cryptocurrency refers to digital 'coins' or assets that are based on block-chain technology. Blockchains are distributed ledger systems where each node of the system is linked together in a peer-to-peer network. All transactions are systematically validated by each component of the network. Blocks, which form the basis for the coins, are created through an initial coin release (or ICO), can be earned through activities (e.g., in gaming, transaction activity), or "mined". Mining usually occurs through 'proof-of-work' systems, whereby cryptographic algorithms generate complex random numbers of hashes which must be solved using the application of computer power. The different parties that contribute to this work (or mine the blocks) receive a fraction of the block (e.g., part of a Bitcoin). Such systems also use 'proof of stake'1 methods based on value-added contributions to the generation of the coins. Coins are traded on exchanges, stored privately in wallets using "keys" or identifiers. ${ }^{2}$ Increasingly, they can be used in tokenised economies to pay for games, to gamble, to pay for commodities, for producing work (e.g., Anytask and Electroneum) or secure contracts (smart contracts, Chainlink) and to coordinate supply chains (e.g., VeChain) or as currency (Reserve Rights or BTC) (Gainsbury \& Blaszczynki, 2017; Scholten, Zendle, \& Walker, 2020).

Cryptocurrency trading has much in common with modern trading on the share-market (Granero et al., 2012; Kim, Hong, Hwang, Kim, \& Han, 2020). It attracts both experienced and less experienced investors; both large institutional investors as well as small retail investors; is subject to market fluctuations; and, trading is heavily automated, with buy and sell orders set by digital trading systems. However, there a number of clear differences. First, trading can occur 24 hours of the day and every day of the week. Second, crypto coins are harder to value. In contrast to mining companies that can state potential earnings (e.g., based on gold deposits or barrels of oil), this more difficult with cryptocurrencies which share many similarities with stocks traded on venture exchanges. With such stocks, there are often only ideas for projects and few tangible assets and realisation of the business models. Crypto projects also often lack statements of profit margins that might be used to estimate future dividend returns. ${ }^{3}$ Instead, future value can only be based on whether investors believe that the coin will attract attention based on whether it has a good reputation and profile, ${ }^{4}$ or whether it has a genuine 'use case' (i.e.,

\footnotetext{
${ }^{1}$ The term proof of stake is similar to the concept of 'money on the table' in business, whereby parties to a transaction demonstrate commitment and trust by staking something of value to the business proposition.

${ }^{2}$ Coins can be stored on exchanges (soft wallet) or on special USB-style external hard drives (hard wallets).

${ }^{3}$ Some crypto projects do offer what are called 'air-drops' which are rewards for holding tokens or for activity on the host platform (e.g., gambling or playing games on certain platform that use a particular token as a currency).

${ }^{4}$ The number of Google searches and Twitter search hits for a coin has been found to correlate with future price behaviour.
}

utility beyond trading). Investors can only look at simple ratios such as the maximum number of coins available vs current supply or the current total market capitalisation as the basis for hypothetical growth. ${ }^{5}$ This is based on the knowledge that some coins have a limited maximum and greater likelihood of price growth, whereas others with an infinite supply (e.g., DOGE coin) are inflationary and lose value as more coins are produced. Like speculative stocks, prices can shift rapidly overnight due to sentiment changes, celebrity endorsements, or single comments and their popularity on platforms such as Reddit. Although there is evidence that price rises in crypto stocks correlate with Twitter activity and have some predictability (see Kraaijeveld \& De Smedt, 2020), many of these other extraneous factors are unpredictable and therefore (like an unexpected run by a horse) has a strong element of randomness or chance.

A third difference is that the crypto market is much more volatile. Prices for single coins can increase over $100 \%$ percent in a matter of hours and then drop back down again soon after (Meng \& Fu, 2020). Even Bitcoin, the dominant coin, can vary substantially in price (e.g., in February 2021 it lost $20 \%$ of its value in 2 days) (Dahham \& Ibrahim, 2020). Markets also move in rapid cycles of boom and bust that are more severe than observed in the standard stock-market. For example, even in well-documented 'bull-runs' (e.g., in 2017), the Bitcoin price suffered multiple corrections of between 30 and $40 \%$. Meanwhile, altcoins often display even more extreme price movements. This creates trading opportunities, but also make them higher risk. In 2017, during the so-called "crypto-bubble", some well-documented coins (e.g., the privacy coin Verge) rose over $100,000 \%$ such that an investment of \$US100 invested at the right time would have become over $\$ 1 \mathrm{~m}$ in under a year. The same coin, along with many others, also fell over $80 \%$ in the bust cycle in 2017-2018 such that many altcoin holders who failed to sell at the peak lost much of their capital gains.

A fourth difference is that crypto trading has the potential create some additional uncertainties that traditional shares often do not create. Many thousands of coins have been produced and many have been scams, whereby coin values have been quickly "pumped" (i.e., artificially inflated in value through means of spreading misinformation) only for the founders to leave the market (Kamps \& Kleinberg, 2018). Crypto can also be used in criminal activities; be the basis of operations with spurious business propositions; and often be subject to inconsistent or "knee-jerk" regulations (e.g., countries might decide to delist certain coins or ban crypto completely such as currently been suggested in India and Nigeria). Crypto owners can also lose their assets (the keys to their coins) through loss of hard wallets, hard-drives,

${ }^{5}$ If the current supply of coins is very much below the total possible supply which can be mined or produced, then this means that the coin value will decrease. Low market cap values are also favoured because it gives a realistic sense of growth. For example, a top 10 market cap will be in the order of $\$ 10-20 \mathrm{~b}$, so that a current market cap of $\$ 100 \mathrm{~m}$ has a more realistic growth potential. 
hacks launched on exchanges, or incorrect use of the technology.

A final characteristic of crypto trading which makes it risky is that it is very difficult to engage in portfolio balancing to protect against risk on the downside. In conventional share trading, investors in speculative or high risk or speculative stocks can also purchase more stable "blue chip" shares which tend to hold their value over a longer period. By contrast, the value of altcoins is pegged to Bitcoin such that they usually only go up or down when BTC changes in price (Balakrishnan, 2020). In effect, this makes them operate more like derivatives ${ }^{6}$ of BTC than independent stocks. ${ }^{7}$ As a result, if BTC suffers a major correction, altcoin value loss will usually be even greater, so that coin holders will have little means of creating a "a balanced portfolio" whereby there may be some hope that some coin move against the overall market trajectory.

\section{Crypto-trading: a form of gambling?}

These many characteristics of crypto trading has led some commentators to suggest that this new activity shares much in common with online gambling (Gainsbury \& Blaszczynski, 2017; Millar, 2018; Mills \& Nower, 2019). Indeed, similar arguments have been raised in relation to the daytrading of shares, which appears to entail a significant element of luck or chance, inconsistent returns, and a likelihood of poor returns for most investors (e.g., Arthur \& Delfabbro, 2016; Arthur, Delfabbro, \& Williams, 2015; Arthur, Williams, \& Delfabbro, 2016; Barber, Lee, Liu, \& Odean, 2009; Dorn, Dorn, \& Sengmueller, 2014; Gao \& Lin, 2015; Jordan \& Diltz, 2003). As Arthur et al. (2015) point out, day-trading differs from conventional long-term share investing in that the event frequency (time between purchase and sale) is often short. Purchases and sales may also be more based on "technical analysis" than appreciation of the intrinsic or long-term value of the stock. Rather like race and sports bettors studying form guides or sporting statistics, day traders study "candles", patterns, or ratios and support levels. While these indicators can often be useful guides to price movements, they often involve ad hoc judgments (the price has already moved up or down) and they are not capable of anticipating sudden market changes. As a result, it is estimated that the majority of coin and day traders do not make returns higher than the market and many lose money (Melker, 2019). Few day-traders of shares last for very long in the market, with only $7 \%$ estimated to last five years in the business.

Research by Arthur and Delfabbro (2016) showed that people who gamble are significantly more likely to engage in day-trading. Similar findings have emerged in relation to

\footnotetext{
${ }^{6} \mathrm{By}$ this, we do not imply that altcoins are derivatives in the traditional sense; only that upward and downward movement are strongly correlated with Bitcoin.

${ }^{7}$ Altcoins move in the direction of BTC, but the rate of change can often be much higher (e.g., 10x or 100x value during a time when BTC might change by $4 \mathrm{x})$.
}

crypto trading, with Mills and Nower (2019) observing, using a sample of gamblers, that those who engaged in sports betting and high-risk stock trading were more likely to report crypto-trading. All of these activities were associated with a higher risk of problem gambling, with problem gambling found to be an independent predictor of crypto-trading after controlling for other associated variables. The authors argued that crypto-trading may be appealing to people who enjoy gambling and may attract similar demographic groups or (often younger males with higher levels of income and education) and people with similar personality or temperaments (Conlin et al., 2015; Dixon, Giroux, Jacques, \& Gregoire, 2018; Kim et al., 2020; Kumar, 2009). These include greater impulsivity and novelty seeking.

These emerging findings and the structural characteristics described above therefore raise important questions about the potential risks inherent in crypto-trading. Accordingly, in this paper we examine how some of the specific structural characteristics of this new activity might assist in understanding how the topic might need to be approached in psychological research. In particular, we examine the ways in which existing insights into online sports betting and day trading can be applied to crypto trading. A particular focus is on whether this activity could potentially lead to excessive behaviour and harm in some individuals, and what specific structural characteristics are likely to be involved. Here we outline some of the most important psychological principles that we believe to be central to understanding the potentially addictive elements of this new behaviour. We then conclude the paper with discussion of some potential protective factors that could mitigate against the primary risk factors.

\section{Risk factors in crypto currency trading}

The illusion of control. Crypto trading, as with day trading and sports betting, is not entirely based on chance. Skill and strategy can make a difference to outcomes. For example, betting on Sheffield United to win the 2021-22 English Premier League or buying a cheap altcoin after a $+30 \%$ daily surge in price during a flat period of the crypto market are both likely to be ill-advised decisions. By contrast, betting on Manchester City and buying altcoins when the price has recently dropped appear to be better decisions. However, all of these activities offer many opportunities for people to over-estimate the role that applying specific types of knowledge or skill might play in outcomes and, conversely, the significant role that luck and chance are likely to play. The illusion of control, defined as a subjective over-estimation of the objective ability to exert control (Langer, 1975 ) is known to be a common feature of gambling (Wohl \& Enzle, 2002; Wood \& Clapham, 2005). People believe that strategies, skills, or certain rituals can increase the probability of winning. Such beliefs are known to be present in both chance and more skilled games and appear to be stronger in people experiencing gambling problems (Jefferson \& Nicki, 2003; Joukhador \& Blaszczynski, 2004; Lambos \& Delfabbro, 2007). 
The illusion of control is likely to be a strong feature of crypto trading and this feature is also likely to be common to sports betting and day trading. The effect is likely to be bolstered by other heuristics and biases, including: biased or self-serving attributions (outcomes due to personal action rather than external factors); hindsight bias (the outcome is seen as being hypothesised all along); and, the hot-hand fallacy (perceptions of predictable momentum shifts or winning periods (Lambos \& Delfabbro, 2007; Toneatto \& Ladouceur, 2003). Many of these effects are likely to be strong during favourable market conditions. If BTC is trending upwards, then nearly all coins will experience growth over time. As a result, traders will rarely be wrong in their choices and most decisions will be positively reinforced. Traders will therefore, often falsely, infer continency between their actions and positive outcomes, an effect which is known to be stronger when the probability of reinforcement is high (Blanco, Matute, \& Vadillo, 2011; Matute, 1996). As a result, traders may gain a sense of invincibility or perception that they cannot lose and this may contribute to greater risk taking, for example: speculation of large amounts in just one speculative coin; not planning for strategies to exit the market at the right time; or, moving money from a more balanced portfolio towards purchasing riskier altcoins.

Social learning and reinforcement. Crypto trading has also emerged during the era of social media. This has led to the emergence of a strong social media culture of crypto advisors, spruikers/influencers and more experienced advisors on platforms such as Youtube. Searching online quickly shows that it is possible to find at least one positive endorsement of at least one major coin. Some of these arise from what appear to be more experienced and wellinformed sources (e.g., the Coin Bureau, Michael van der Poppe), but there are many others that are entirely speculative, ill-informed, and potentially misleading because they leave out key information (a coin might have a low market cap which suggests growth potential, but only $10 \%$ of the total supply of coins has been produced). Although similar promotional information has historically been available concerning conventional shares, the volume of material, the interactivity and superficial confidentiality of the information (i.e., the sense that one is in the know first, or is getting some special insights) is much stronger. Promoters of particular coins can show evidence of how much money they have already earned from buying in very low, and they can use graphics with great effect to show the anticipated growth. This can serve to create a sense of urgency and a need for immediate action. It also encourages a culture of mutual social reinforcement in which followers of channels seek to promote their successes, while also reading about the gains scored by others.

Preoccupation. Preoccupation or salience is a recognised feature of most major conceptual models of addiction (e.g., Browne \& Rockloff, 2019; Griffiths, 2005). Those who engage excessively in a particular activity often find it difficult to disengage from the activity. They may continuously think about the activity (preoccupation) and prioritize the activity ahead of other important responsibilities. Crypto trading would appear to be an activity that has the potential to be highly absorbing. Like day-trading, it involves regular scrutiny of price movements, news and other online media about coin-related developments (e.g., coin 'burns'), the need to make regular buy and sell decisions and research into the different coins (their potential value, market cap, number and reputation) (Dixon et al., 2018). However, because crypto markets operate continuously, it is possible for people to be engaged with the activity at any hour of the day. By contrast, sports bettors (unless they bet on many different activities) often have to wait for matches to occur. Day-traders can only be actively engaged with the activity in the sense of buying and selling during daylight hours. This creates the potential for crypto trading to absorb a considerable amount of time and potentially with greater risk of disruptions to sleep and other daily commitments.

\section{Fear of Missing Out (FOMO)}

One of the strongest psychological factors that appears to influence crypto-trading is the fear of missing out (FOMO). This term is often used by some experienced traders and a style of thinking to avoid (Przybylski, Murayama, DeHaan, \& Gladwell, 2013). Although FOMO is likely to be a feature of online sports betting (e.g., the belief that one could be missing a good bet), the opportunities for FOMO seem particularly intensified in crypto-trading. Traders are confronted with displays of hundreds of coins. Some of them, they already own; others they do not. If one which they have purchased is going up rapidly, they may regret having not made a larger investment. If another unpurchased coin is going up which they had previously considered, they feel annoyed for having missed out on the opportunity. Perhaps most problematically of all is the situation, when they observe a 'green screen of numbers'. The market is going up and they feel compelled to be part of the action. They purchase a coin when it has reached a short-term peak, only to watch the price fall soon afterwards. FOMO also applies to sell decisions. When altcoins, in particular, have rapidly increased in price (e.g., 10X), there is always the prospect that the rise might continue. Instead of taking the profit, the person starts to dream of what they might purchase if the price increases $40 \mathrm{X}$ or $50 \mathrm{X}$, but is then unprepared when the price falls $30-40 \%$ in single day when the bull-run ends.

FOMO is a construct that largely arose from social media research and this is reflected in its associated measure (Przybylski et al., 2013). In this sense, it is entirely appropriate to apply to crypto-trading given its strong presence in online social networks. Not only do individual traders or investors experience a FOMO in relation to their own actions, they are also exposed to testimonials from other traders on social media sites that may then encourage them to buy certain coins or to hang on to receive even larger gains. In the notorious $100,000 \mathrm{X}$ ascent of Verge coin in the 2017-18 bull-run, many traders were discouraged from 
selling because of discussion of even greater potential profits on social media communities. Even when the coin was falling in value, some almost felt obliged to keep the faith and not sell out, even though this would have been in their individual best interest to take even a $50 \%$ or $30 \%$ profit when the coin's value fell rapidly.

\section{Anticipated regret}

Cognitive psychology has recognised for some time that many decisions are based on the desire to minimise anticipated regret (Miller \& Taylor, 1995; Schwartz et al., 2002). One of the central findings in this area is that acts of commission (doing something) usually led to stronger feelings of regret than acts of omission (not doing something). This asymmetry has been used to explain why people are reluctant to sell shares which they have held for some time, why they avoid hitting on 16 in blackjack (Miller \& Taylor, 1995), and why people will value lottery tickets held for a long time as being more valuable than those held for a shorter period (Bar-Hillel \& Neter, 1995; van den Ven \& Zeelenberg, 2011). Acts of commission involving regret in trading would include decisions where a stock or coin holding is sold, only for it to rapidly appreciate in value. Acts of omission involve situations where ultimately successful stocks or coins were forgone (not purchased) for other investment decisions.

It is clear that both acts are likely to cause significant regret in trading and that this may potentially be a risk factor that is more strongly observed in this activity than in most forms of gambling, with the exception of wagering. In the gambling context, perhaps the most regretful event that might be imagined would be a failure to buy (or to lose) a lottery ticket in a particular week when the winning numbers came up. Most other gaming activities, including the higher risk ones (e.g., gaming machines, card games) are less likely to involve situations where a person might consider themselves to blame for missing out on a win. A reason for this is that the games are usually of a short duration, and decisions made in one game have no bearing on outcomes of future games. By contrast, crypto trading allows traders to observe the folly of their decisions over a long period of time: what they missed out on (a coin that has $100 \mathrm{x}$ in value in 6 months), and what coins they sold too early. For this reason, the act of commission and omission effects are both likely to be very strong. However, importantly, given the very strong FOMO effects often described as being the downfall of less experienced investors (who buy into upwards trends), a question arises as to whether the asymmetry between commission vs. omission based regret observed in other contexts is as strongly observed in crypto trading.

\section{Protective factors and strategies}

As the popularity of crypto trading rapidly increases over the next 12 months, it is important to identify what psychological and other strategies might be used to mitigate against the risks inherent in this new activity. How can it be kept enjoyable, potentially productive without reducing a person's quality of life? General strategies for avoiding harm associated with excessive trading share some similarities with gambling: sticking to a budget; not spending more than can be afforded; and not chasing losses (losses are, in fact, usually a useful tax offset; e.g., see 'cryptocurrency as an investment'; www.ato.gov.au). Similarly, it is possible to dispel some of the erroneous beliefs associated with the activity, including the degree to which outcomes can be predicted or controlled. Specifically, to temper over-estimated perceptions of control, new investors need to be aware that crypto value is highly correlated with BTC, so that it is unlikely that altcoins will rise unless BTC is rising as well. In effect, even coins based on high quality projects with good fundamental use cases may not rise unless BTC is stable and investors are confident about the overall health of the market. This means that protection against downside risk is almost more challenging than for conventional share trading. The best a person can do is to take profits at appropriate times, maintain some liquidity (e.g., convert currencies into USD stable coins) and focus on investments in projects that are likely to have greatest longevity.

Protection against social influences is also important. Many YouTube channels and social media opinion (e.g., on Reddit) often involves preaching to a converted audience. Evidence is posted in support of certain coin purchases, but often without any fundamental analysis, critical evaluation of downsides, or consideration of opportunity cost (are there better purchases that might be made). Such information may be circulated rapidly and may even be exploited by bad actors using bots or other means to amplify certain messages to encourage buying coins to manipulate the market. Community education around the need to seek out reputable and multiple information sources, including the appropriate magnitude of investment, may therefore be important in the near future. Inexperienced investors may also need to be taught about the history or longer-time horizons for this market. Many panicked in response to negative news (e.g., the May 2021 Tweets from Tesla CEO, Elon Musk about divesting from Bitcoin payments) even though this would have had negligible impact on the market.

Preoccupation or salience is a difficult issue to address if a person is a professional trader and needs to study price movements throughout the day. However, for community or general retail investors, it is important to recognise that continual monitoring can be an easy habit to develop even among casual investors. This may begin as a temptation to check that then becomes an unconscious or automatic tendency to study price movements during work, during social activities, education, and even during the night. This activity can disrupt sleep, productivity and be an ongoing distraction. In this way, crypto trading has the potential to combine the financially speculative elements of gambling with social media (e.g., Facebook update checking). Strategies for dealing with this temptation might involve setting limits or rules on when, or how often, the prices are checked. Other activities might be scheduled ahead of price monitoring, so that checking prices only occurs as a type of reward for completing other work. 
The principal harm associated with FOMO and regret is that people may impulsively place more money than they can afford on risky coins that have already undertaken rapid growth. As a result, they face a greater risk of buying into the market when it is due for a major correction (historically this occurs when the BTC dominance or \% of total market cap is lower). Important advice that can reduce this effect is to encourage satisficing (Schwartz et al., 2002) in which people are discouraged from expecting optimal or perfect decision-making. Even experienced traders will not always buy at the lowest price or sell at the highest price. Nor will they pick up every coin that displays very high growth. Instead, the aim is to encourage protective strategies: buy before things are too high; buy the dips or corrections to minimise downside risk; and, stay focused on the positive outcomes rather than the outcomes that were missed. Achievement of at least some very good outcomes in a rising market is likely to be increased if the portfolio is spread over a wider range of coins, but, as mentioned, cannot protect against sudden downturns in the BTC price.

\section{CONCLUSIONS}

Crypto trading is a rapidly growing activity that is likely to receive increasing mainstream acceptance over the next few years. We believe that the topic is important in behavioral addiction research for two reasons. The first is because it brings together elements of risk inherent in gambling, but also in excessive social media use. Particular features that make this form of speculation unique include its 24-hour availability, long-form nature, the extreme volatility of outcomes, and the strong influence of sentiment and social influence. In this sense, it has the potential to be riskier for inexperienced traders whose engagement in the market has been strongly influenced by media attention or FOMO sentiments. A second issue is that crypto trading provides many opportunities to examine the operation of many established principles of social and cognitive psychology. Opportunities exist to profile the distinct risk factors that differentiate crypto trading from other similar activities (day trading and online sports wagering), but also to identify protective factors that can avoid the development of the various harms that might arise when large numbers of inexperienced investors enter the market. Research programs examining these factors are likely to be influential to discussions of consumer protections and inform potential steps for regulation of trading platforms and other activities that involve cryptocurrencies.

Funding sources: This paper was funded independently with no support from government, industry or party external to the University.

Authors' contribution: Initial drafting of paper (PD); Revisions and editing (DK, JW)

Conflict of interest: None to declare

\section{REFERENCES}

Arthur, J. N., \& Delfabbro, P. (2016). Day traders in South Australia: Similarities and differences with traditional gamblers. Journal of Gambling Studies, 33(3), 855-866. https://doi.org/10. 1007/s10899-016-9659-x.

Arthur, J. N., Delfabbro, P., \& Williams, R. J. (2015). Is there a relationship between participation in gambling activities and participation in high-risk stock trading? Journal of Gambling Business and Economics, 9(3), 34-53. https://doi.org/10.5750/ jgbe.v9i3.1034.

Arthur, J. N., Williams, R. J., \& Delfabbro, P. (2016). The conceptual and empirical relationship between gambling, investing, and financial market speculation. Journal of Behavioural Addictions, 5(4), 580-591. https://doi.org/10.1556/2006.5.2016. 084.

Balakrishnan, A. (2020). Understanding how altcoins are tied to bitcoin. https://freebitco.in/site/blogs/bitcoin/how-altcoins-aretied-to-bitcoin/. Accessed 10th March 2021.

Bar-Hillel, M., \& Neter, E. (1996). Why are people reluctant to exchange lottery tickets? Journal of Personality and Social Psychology, 70(1), 17-27. https://doi.org/10.1037/0022-3514.70.1.17.

Barber, B. M., Lee, Y. T., Liu, Y. J., \& Odean, T. (2009). Just how much do individual investors lose by trading? Review of Financial Studies, 22 (2), 609-632. https://doi.org/10.1093/rfs/ hhn046.

Blanco, F., Matute, H., \& Vadillo, M. A. (2011). Making the uncontrollable seem controllable: The role of action in the illusion of control. The Quarterly Journal of Experimental Psychology, 64(7), 1290-1304. https://doi.org/10.1080/17470218.2011.552727.

Browne, M., \& Rockloff, M. J. (2020). Measuring behavioural dependence in gambling: A case for removing harmful consequences from the assessment of problem gambling pathology. Journal of Gambling Studies, 36(4), 1027-1044. https://doi.org/ 10.1007/s10899-019-09916-2.

Conlin, A., Kryrolainen, P., Kaakinen, M., Jarvelin, M. R., Perrttunen, J., \& Svento, R. (2015). Personality traits and stock market participation. Journal of Empirical Finance, 33, 34-50. http://dx.doi.org/10.1016/j.jempfin.2015.06.001.

Crypto.com (2021). Measuring global crypto users. A study to measure market size based using on-chain metrics. Crypto.com. Accessed 10th March 2021.

Dahham, A. Z. D., \& Ibrahim, A. A. (2020). Effects of volatility and trend indicator for improving price prediction of cryptocurrency. IOP Conference Series: Materials Science and Engineering, 928, article 032043.

Dixon, M. R., Giroux, I., Jacques, C., \& Gregoire, P. (2018). What characterizes excessive online stock trading? A qualitative study. Journal of Gambling Issues, 38(May), 8-26. https://doi. org/10.4309/jgi.2018.38.2.

Dorn, A. J., Dorn, D., \& Sengmueller, P. (2014). Trading as gambling. Management Science, 61(10), 2376-2393. https://doi. org/10.1287/mnsc.2014.1979.

Gainsbury, S., \& Blaszczynski, A. (2017). How blockchain and cryptocurrency technology could revolutionize online gambling. Gaming Law Review, 21(7), 482-492. https://doi.org/10.1089/ glr2.2017.2174. 
Gao, X., \& Lin, T. C. (2015). Do individual investors treat trading as a fun and exciting gambling activity? Evidence from repeated natural experiments. Review of Financial Studies, 28(7), 21282166. https://doi.org/10.1093/RFS/HHU075.

Granero, R., Tarrega, S., Fernandez-Aranda, F., Aymami, N., Gomez-Pena, M., Moragas, L., Orekhova, L., Savvidou, L. G., . . . Jiménez-Murcia, L. (2012). Gambling on the stock market: An unexplored issue. Comprehensive Psychiatry, 53(6), 666-673. https://doi.org/10.1016/j.comppsych.2011.12.004.

Griffiths, M. D. (2005). A 'components' model of addiction within a biopsychosocial framework. Journal of Substance Use, 10(4), 191-197. https://doi.org/10.1080/14659890500114359.

Independent Reserve. (2020). IRCI 2020. Cryptocurrency index. https://www.independentreserve.com/static/independentreserve-cryptocurrency-index-irci-2020.pdf.

Jefferson, S., \& Nicki, R. (2003). A new instrument to measure cognitive distortions in video lottery terminal users. The Informational Biases Scale (IBS). Journal of Gambling Studies, 19(4), 387-403. https://doi.org/10.1023/A:1026327926024.

Jordan, D. J., \& Diltz, J. D. (2003). The profitability of day traders. Financial Analysts Journal, 59(6), 85-95. https://doi.org/10. 2469/faj.v59.n6.2578.

Joukhador, J., Blazczynski, A., \& Maccallum, F. (2004). Superstitious beliefs in gambling among problem and non-problem gamblers: Preliminary data. Journal of Gambling Studies, 20(2), 171-180. https://doi.org/10.1023/B:JOGS.0000022308.27774.2b.

Kamps, J., \& Kleinberg, B. (2018). To the moon: Defining and detecting cryptocurrency pump-and-dumps. Crime Science, 7, 1-18. https://doi.org/10.1186/s40163-018-0093-5.

Kim, H. J., Hong, J. S., Hwang, H. C., Kim, S. M., \& Han, D. H. (2020). Comparison of psychological status and investment style between bitcoin investors and share investors. Frontiers in Psychology, 11, article 502295. https://doi.org/10.3389/fpsyg. 2020.502295.

Kraaijeveld, O., \& De Smedt, J. (2020). The predictive power of public Twitter sentiment for forecasting cryptocurrency prices. Journal of International Financial Markets, Institutions and Money, 65, March, Article 101188. https://doi.org/10.1016/j. intfin.2020.101188.

Kumar, A. (2009). Who gambles in the stock market? The Journal of Finance, 64(4), 1889-1933. https://doi.org/10.1111/j.15406261.2009.01483.x.

Lambos, C., \& Delfabbro, P. H. (2007). Numerical reasoning ability and irrational beliefs in problem gambling. International Gambling Studies, 7(2), 157-172. https://doi.org/10.1080/ 14459790701387428.

Langer, E. J. (1975). The illusion of control. Journal of Personality and Social Psychology, 32(2), 311-328. http://dx.doi.org/10. 1037/0022-3514.32.2.311.

Matute, H. (1996). Illusion of control: Detecting response-outcome independence in analytic but not in naturalistic conditions.
Psychological Science, 7(5), 289-293. https://doi.org/10.1111/j. 1467-9280.1996.tb00376.x.

Melker, S. (2019). Day trading bitcoin: Why $95 \%$ of traders lose money and fail. https://cointelegraph.com/news/day-tradingbitcoin-why-95-of-traders-lose-money-and-fail. Accessed 10th March 2021.

Meng, J., \& Fu, F. (2020). Understanding gambling behavior and risk attitudes using cryptocurrency based casino blockchain data: Gambling behaviour and risk attitudes. Royal Society Open Science, 7, article 201446. https://doi.org/10.1098/rsos. 201446.

Millar, S. I. (2018). Cryptocurrency expands online gambling. Gaming Law Review, 22(3), 174-174. https://doi.org/10.1089/ glr2.2018.2232.

Miller, D., \& Taylor, B. R. (1995). Counterfactual thought, regret and superstition: How to avoid kicking yourself. In N. J. Roese, \& J. M. Olson (Eds.), What might have been: The social psychology of counterfactual thinking (pp. 305-332). Mahweh, NJ: Lawrence Erlbaum Associates, Publishers.

Mills, D. J., \& Nower, L. (2019). Preliminary findings on cryptocurrency trading among regular gamblers: A new risk for problem gambling. Addictive Behaviors, 92(5), 136-140. https:// doi.org/10.1016/j.addbeh.2019.01.005.

Przybylski, A., Murayama, K., DeHaan, C. R., \& Gladwell, V. (2013). Motivational, emotional, and behavioral correlates of fear of missing out. Computers in Human Behavior, 29(4), 1841-1848. https://doi.org/10.1016/j.chb.2013.02.014.

Scholten, O. J., Zendle, D., \& Walker, J. A. (2020). Inside the decentralised casino: A longitudinal study of actual cryptocurrency gambling transactions. Plos One, article e0240693. https://doi.org/10.1371/journal.pone.0240693.

Schwartz, B., Ward, A., Monteross, J., Lyubomirsky, S., White, K., \& Lehman, D. (2002). Maximizing vertus satisficing: Happiness is a matter of choice. Journal of Personality and Social Psychology, 83, 1178-1197. https://doi.org/10.1037/0022-3514.83.5. 1178.

Toneatto, T., \& Ladouceur, R. (2003). The treatment of pathological gambling: A critical review of the literature. Psychology of Addictive Behaviors, 17(4), 284-292. https://doi.org/10.1037/ 0893-164X.17.4.284.

van den Ven, N., \& Zeelenberg, M. (2011). Regret aversion and the reluctance to exchange lottery tickets. Journal of Economic Psychology, 32(1), 194-200. https://doi.org/10.1016/j.joep.2010. 11.008.

Wohl, M. J. A., \& Enzle, M. E. (2002). The deployment of personal luck: Sympathetic magic and illusory control in games of pure chance. Personality \& Social Psychology Bulletin, 28(10), 13881397. https://doi.org/10.1177/014616702236870.

Wood, W. S., \& Clapham, M. M. (2005). Development of the drake beliefs about chance inventory. Journal of Gambling Studies, 21(4), 411. https://doi.org/10.1007/s10899-005-5556-4. 